\title{
PHOSPHORYLATED CARBOHYDRATE INTERMEDIATES OF THE HUMAN ERYTHROCYTE DURING STORAGE IN ACID CITRATE DEXTROSE. I. EFFECT OF THE ADDI- TION OF INOSINE AT THE BEGINNING OF STORAGE *
}

\author{
By A. WILLIAM SHAFER AND GRANT R. BARTLETT
}

(From The Scripps Clinic and Research Foundation, La Jolla, Calif.)

(Submitted for publication January 9, 1961 ; accepted March 16, 1961)

The post-transfusion survival of stored human or rabbit erythrocytes can be influenced favorably by the addition of certain purine nucleosides to the preserving solution (1-5). It had been noted earlier that the water-soluble organic phosphates of the erythrocyte disappeared to a large extent during storage (6), but nucleosides have been found to retard this change and, if added late in storage followed by a short incubation at $37^{\circ} \mathrm{C}$, they bring about appreciable resynthesis of the organic phosphate $(7-10)$.

Early studies on the nature and changes of the phosphate compounds of the erythrocyte during storage were performed for the most part by using hydrolysis rates and paper chromatography $(1,2,7-9)$. Recently improved technics for the isolation and identification of the metabolic intermediates, which use columns of ion exchange resin and more specific chemical and enzyme analytical methods, have greatly extended our knowledge of the normal carbohydrate intermediates of the human erythrocyte and make possible a more detailed analysis of changes occurring during storage (11-18).

We have previously reported on the phosphorylated carbohydrate intermediates of the rabbit erythrocyte during storage with and without inosine (19). The present paper describes a similar study in which the glycolytic intermediates and nucleotides of human erythrocytes were analyzed at biweekly intervals during 8 weeks of storage at $4^{\circ} \mathrm{C}$ in acid citrate dextrose (ACD) and in ACD plus inosine (ACDI).

\footnotetext{
* Supported by the US Army Medical Research and Development Command, Office of the Surgeon General, and by the National Heart Institute.
}

\section{METHODS}

From each of 2 healthy male donors who had normal blood counts, $480 \mathrm{ml}$ of blood was drawn by vacuum into standard blood storage bottles containing $120 \mathrm{ml}$ of ACD (NIH formula B). Inosine which had been autoclaved in normal saline in a concentration of $40 \mathrm{mg}$ per $\mathrm{ml}$ was added to one sample in the amount of $4 \mathrm{mg}$ (15 $\mu$ moles) per $\mathrm{ml}$ of blood; $100 \mathrm{ml}$ of the ACD-blood mixture was removed aseptically from each sample for assay immediately and after $2,4,6$, and 8 weeks of storage at $4^{\circ} \mathrm{C}$.

The blood samples were centrifuged, plasma and buffy coat removed, and the erythrocytes washed once with normal saline. The erythrocytes were mixed with 2 vol of 10 per cent trichloroacetic acid (TCA), the mixture centrifuged, and the precipitate re-extracted with 5 per cent TCA. The above procedures were carried out in the cold. The TCA was removed with ether. The erythrocyte extracts were neutralized, diluted 4-fold, and run through $1 \times 15 \mathrm{~cm}$ columns of Dowex $1 \times 8$ chloride ( 60 to 80 wet mesh). The columns were eluted at a rate of $2.5 \mathrm{ml}$ per minute with solutions of $\mathrm{HCl}$ and $\mathrm{NH}_{4} \mathrm{Cl}$, as shown in Figures 1 and 2, which were collected in approximately $20-\mathrm{ml}$ aliquots. The fractions eluted with $\mathrm{HCl}$ were neutralized shortly after collection. To improve the separation, the compounds in the 0.01 and $0.02 \mathrm{~N} \mathrm{HCl}$ elution sections were rechromatographed on columns of Dowex 1-formate. The eluates of each section were combined, diluted 4-fold and passed through $1 \times 15 \mathrm{~cm}$ columns of Dowex $1 \times 8$-formate (100 to 325 wet mesh) and eluted with linearly increasing concentrations of formic acid or ammonium formate buffer.

All fractions were analyzed for total phosphorus and for optical density at $260 \mathrm{~m} \mu$. The phosphorus peaks were identified tentatively by their elution positions as determined previously with reference compounds. $\mathrm{Nu}$ cleotides were identified by their ultraviolet spectra and by the ratio of adenine to total phosphorus to ribose. The sugar phosphates were identified by their reactions in the anthrone (20), carbazole (21), cysteine-sulfuric acid (22), and orcinol (23) reactions. Confirming enzyme assays were carried out for adenosine triphosphate (ATP) with hexokinase, for adenosine diphosphate 


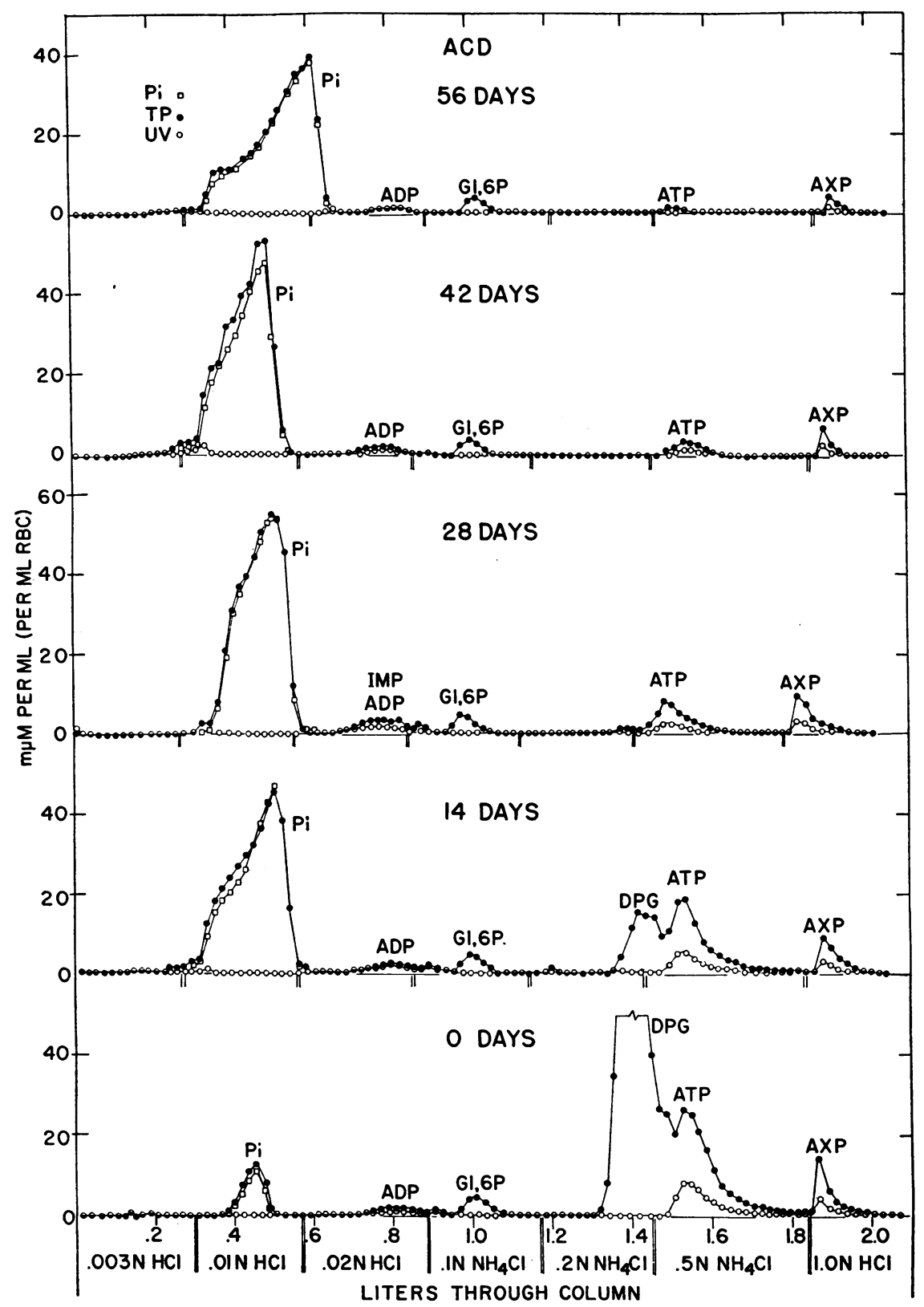

Fig. 1. ION-EXChANGe CHROMATOGRAPHS OF TRICHLOROACETIC ACID EXTRACTS OF HUMAN ERYTHROCYTES STORED IN ACID CITRATE DEXTROSE (ACD) FOR 0, 14, 28, 42, AND 56 DAYs. The data are plotted in $\mathrm{m} \mu$ moles per $\mathrm{ml}$ of eluate (calculated for $1 \mathrm{ml}$ of erythrocytes). Total phosphorus (TP), 9 ; adenine (from the optical density at $260 \mathrm{~m} \mu), O$; inorganic phosphate $(\mathrm{Pi}), \square$. Abbreviations: G1,6P, glucose-1,6-diphosphate: DPG, 2,3-diphosphoglycerate; ADP, adenosine diphosphate; IMP, inosine monophosphate; ATP, adenosine triphosphate; AXP, unknown nucleotide.

(ADP) with hexokinase and myokinase, and for glucose-6-phosphate with glucose-6-phosphate dehydrogenase.

More detailed descriptions of the methods are given elsewhere (11-14) and are the same as those we used previously in a similar study of rabbit blood (19).

\section{RESLLTS AND DISCUSSION}

The results of assays of blood stored in ACD alone and in ACDI are presented in Figures 1 and 2. The results are summarized in Figure 3. 
In both samples there was a precipitous fall in concentration of organic phosphate and a reciprocal increase in inorganic phosphate. The change was less marked in the blood stored in ACDI.

As had been noted previously, diphosphoglycerate proved quite labile to the conditions of storage $(19,24)$. Its concentration fell rapidly in ACD so that after 2 weeks only 18 per cent of the initial level of $8.75 \mu$ moles (all data are presented as $\mu$ moles of phosphorus per $\mathrm{ml}$ of erythrocytes) remained, and none was present at 6 and 8 weeks of storage. The rate of decrease in ACDI was less and 51,27,14, and 9 per cent remained at $2,4,6$, and 8 weeks of storage.

ATP disappeared at a slower rate than did diphosphoglycerate, and the difference between blood stored in ACD and in ACDI was less striking than that found for diphosphoglycerate. The concentrations of ATP at the 0,4 , and 8 week assay periods for blood stored in ACD were 2.7, 0.82 , and 0.17 and in ACDI 2.34, 1.01, and 0.43 $\mu$ moles.

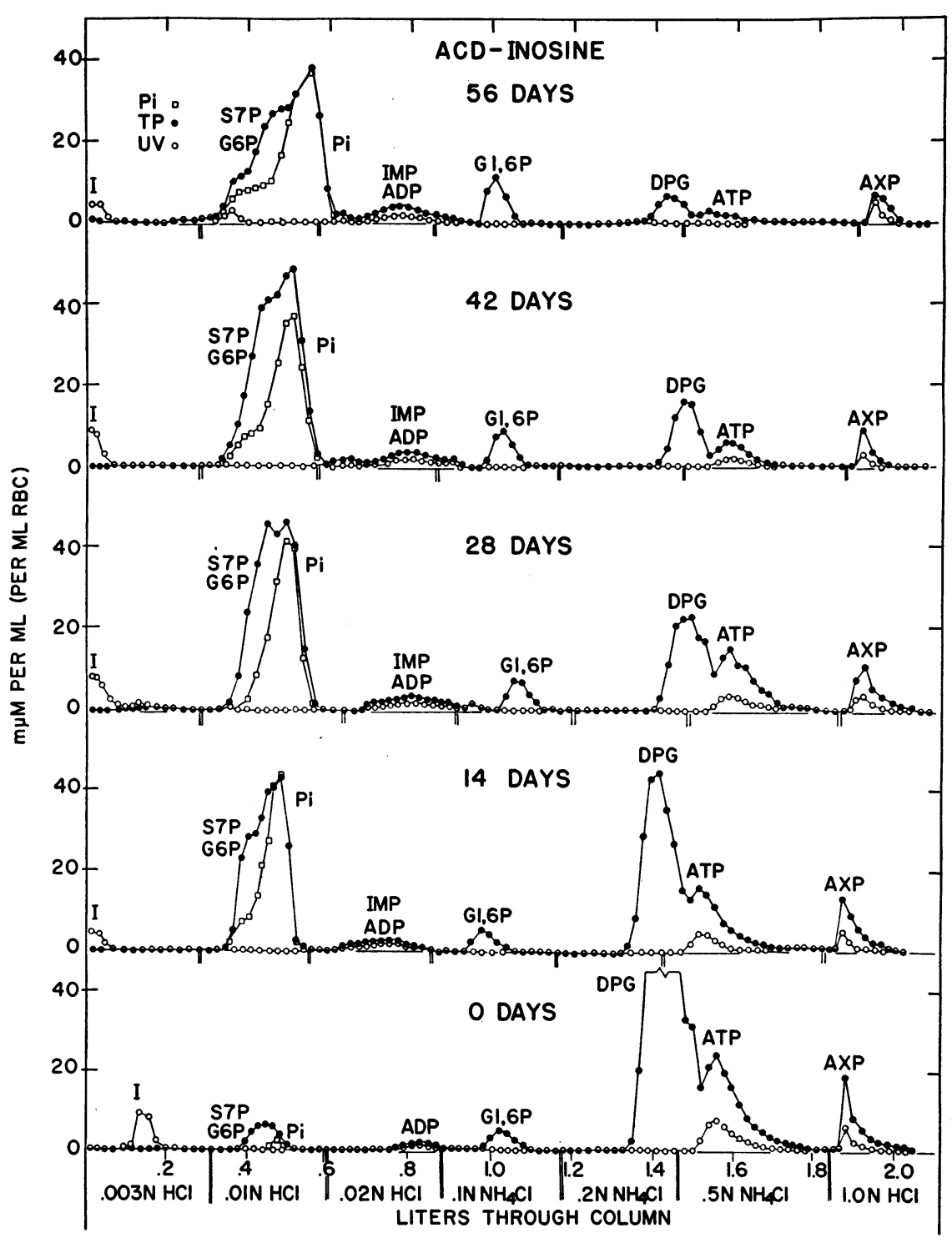

Fig. 2. ION-EXChANGE CHROMATOGRAPHS OF TRICHLOROACETIC ACID EXTRACTS OF HUMAN ERYTHROCYTES STORED IN ACD PLUS INOSINE FOR 0, 14, 28, 42, AND 56 DAYS. See Figure 1. I, inosine; G6P, glucose-6-phosphate; S7P, sedoheptulose-7-phosphate. 
BLOOD STORED IN ACD AT $4^{\circ}$

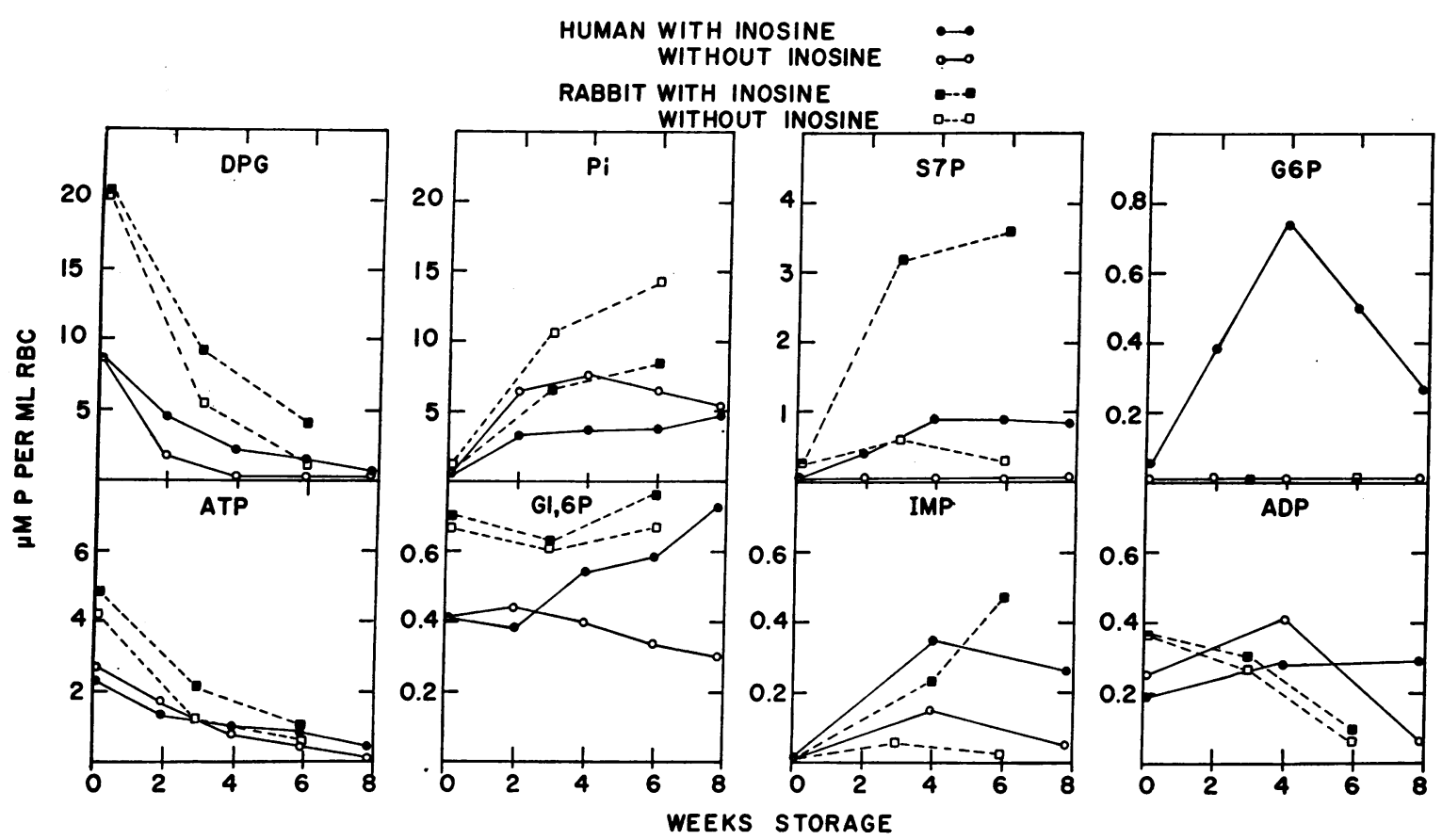

Fig. 3. Changes in phosphate compounds of rabbit and human erythrocytes stored in ACD AND IN ACD PLUS INOSINE. The data are plotted in $\mu$ moles of phosphorus per $\mathrm{ml}$ of erythrocytes (RBC). For abbreviations see Figures 1 and 2.

We have reported previously that fructose diphosphate disappeared immediately after the addition of rabbit or human blood to ACD and that it was absent throughout storage $(19,24)$. In the present study also no fructose diphosphate was found at any time-period in either incubation solution. Glucose diphosphate decreased gradually during storage in ACD so that after 8 weeks, 74 per cent of the initial level remained. In ACDI the level of glucose diphosphate remained constant early in storage and then increased at the 4 and 8 week assay times to 128 and 173 per cent of the initial level.

To improve the separation of the sugar monophosphates, the $0.01 \mathrm{~N} \mathrm{HCl}$ elution sections were rechromatographed on columns of Dowex 1-formate. In the blood stored in ACD, only traces of sugar monophosphates were found at any time. In ACDI, Figure 4, the inorganic phosphate was preceded by a peak of phosphorus which proved to be a mixture of glucose-6-phosphate and sedoheptulose-7-phosphate. The concentration of glucose-6-phosphate reached a maximum of 0.73 $\mu$ moles at 4 weeks and then fell to 0.29 at 8 weeks.
The concentration of sedoheptulose-7-phosphate increased to a maximum of $0.95 \mu$ moles after 4 weeks of storage and subsequently decreased slightly.

The $0.02 \mathrm{~N} \mathrm{HCl}$ elution sections contained a mixture of compounds-chiefly inosine monophosphate and ADP. For better resolution these sections of the 0,4 , and 8 week assays were rechromatographed on columns of Dowex 1-formate. The results are presented in Figure 5. At zero time these sections were composed primarily of ADP. In blood stored in ACD the level of ADP increased at 4 weeks, but at 8 weeks it had dropped to approximately 50 per cent of the initial concentration. In ACDI the concentration of ADP increased slightly at 4 weeks and then remained the same. Inosine monophosphate, which was not present initially, was found in a concentration of $0.15 \mu$ moles in ACD and 0.32 in ACDI at 4 weeks. After 8 weeks of storage the concentration had not changed in ACDI, but it had almost disappeared in ACD.

The peaks labeled AXP in Figures 1 and 2 included a mixture of compounds which have not 
been identified. There appeared to be no appreciable differences in this mixture in the two preserving solutions during storage.

Important negative findings were: 1 ) the lack of accumulation of monophosphoglycerate, glycerate, phosphopyruvate, and pyruvate in the erythrocytes in spite of the marked decrease in concentration of diphosphoglycerate; 2) the lack of significant increase in ADP or adenosine monophosphate in spite of the decrease in concentration of ATP; and 3) the absence of compounds of the pentose shunt other than sedoheptulose-7-phosphate in blood stored in ACDI.

The results which we had obtained previously with rabbit blood were qualitatively similar to those described above for human blood, but there were some interesting quantitative differences, as shown in Figure 3 . In the rabbit erythrocyte the initial concentrations of diphosphoglycerate and ATP were higher than in the human, and the rate of decrease during storage was faster. Sedoheptulose-7-phosphate accumulated in both rabbit and human erythrocytes, but in a much higher concentration in the rabbit. Glucose-6-phosphate increased in the human erythrocyte during storage, but no more than traces of this compound were present in the rabbit.

\section{SUM MARY}

The phosphorylated carbohydrate intermediates of the human erythrocyte were assayed by ionexchange chromatography after $0,2,4,6$, and 8 weeks of storage at $4^{\circ} \mathrm{C}$ in acid citrate dextrose (ACD) with or without inosine (ACDI). The breakdown of diphosphoglycerate and adenosine triphosphate accounted for most of the fall in con-

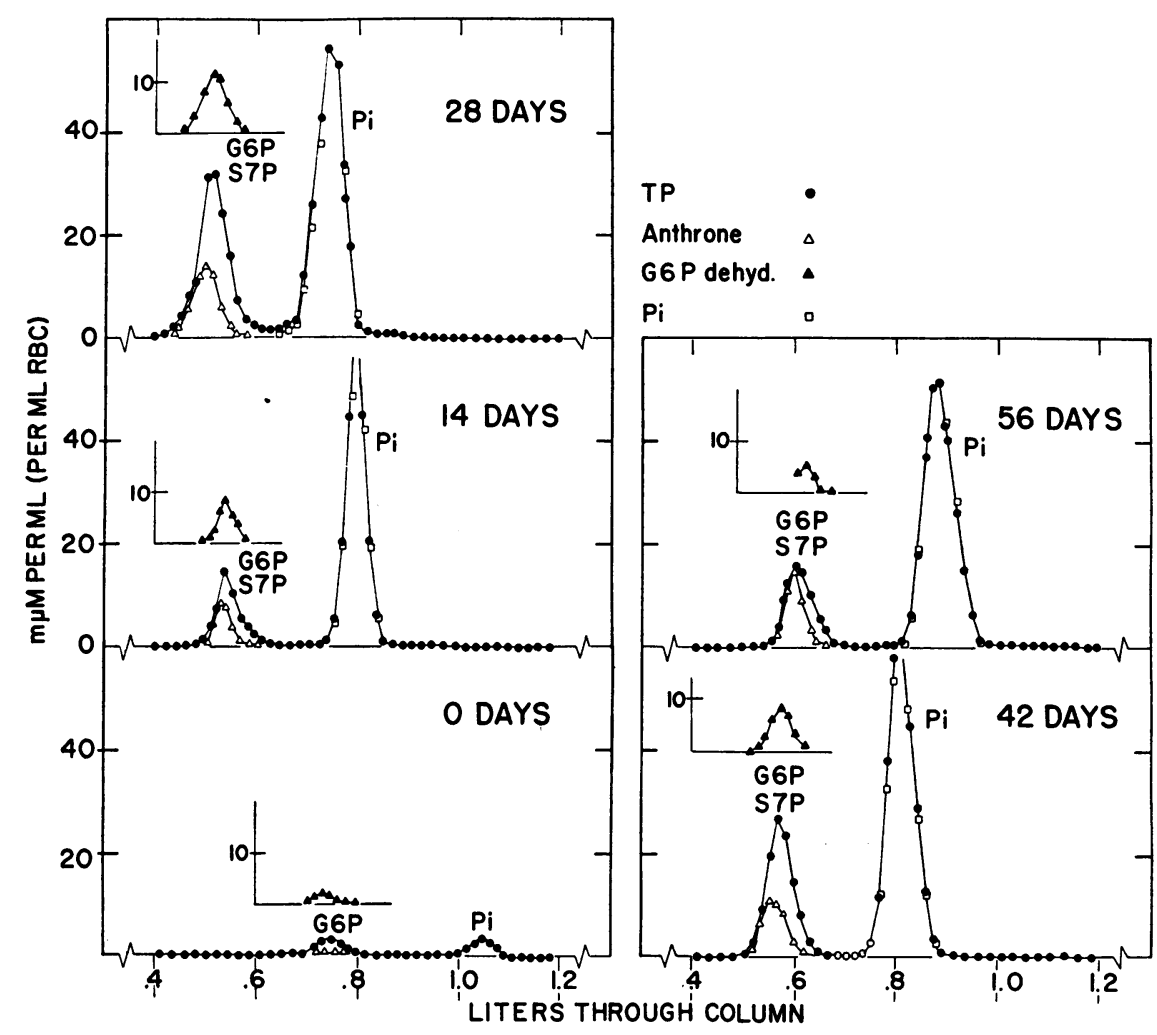

Fig. 4. Rechromatographs of the $0.01 \mathrm{~N}$ HCl elution sections of the Dowex CHLORIDE CHROMATOGRAPHS SHOWN IN FigURe 2 (ERYthrocytes STORED IN ACDI). The pooled eluates were passed through $1 \times 15 \mathrm{~cm}$ columns of Dowex $1 \times 8$-formate (100 to 325 wet mesh) which were eluted at $1 \mathrm{ml}$ per minute with $2 \mathrm{~L}$ of linear gradient zero to $1 \mathrm{~N}$ formic acid. The data are plotted in $\mathrm{m} \mu$ moles per $\mathrm{ml}$ of eluate (calculated for $1 \mathrm{ml}$ of erythrocytes). Abbreviations: see Figures 1 and 2; G6P dehyd., glucose-6-phosphate dehydrogenase; anthrone, colorimetric test for sugars. 


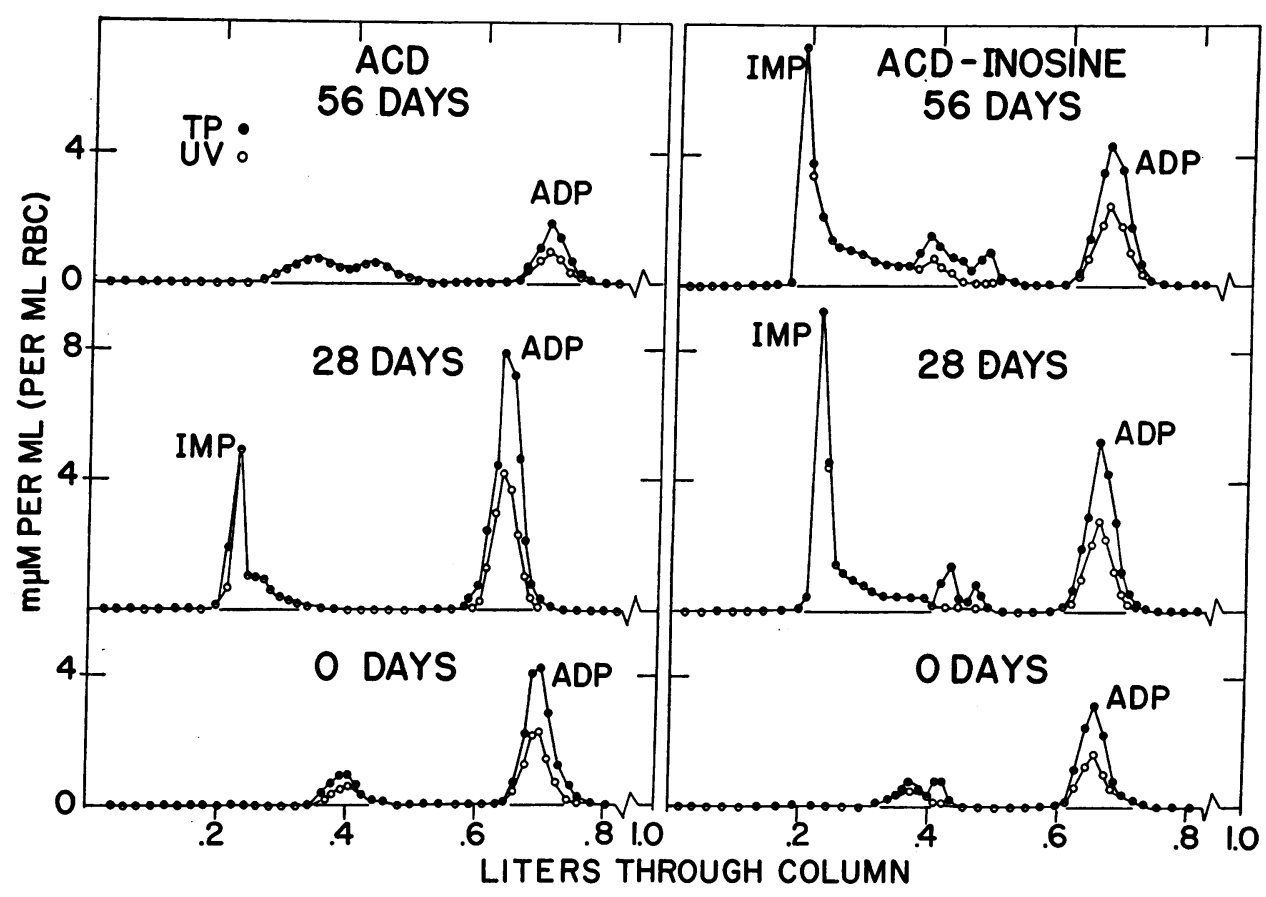

Fig. 5. Rechromatographs of the $0.02 \mathrm{~N}$ HCl elution sections of the Dowex chloride CHROMATOGRAPHS SHOWN IN Figures 1 AND 2. The pooled eluates were passed through $1 \times 15 \mathrm{~cm}$ columns of Dowex $1 \times 8$-formate (100 to 325 wet mesh) which were eluated at 1 $\mathrm{ml}$ per minute with $1 \mathrm{~L}$ of linear gradient zero to $1 \mathrm{~N}$ ammonium formate. See Figure 1 for abbreviations.

centration of organic phosphate and the associated increase in inorganic phosphate. These changes were retarded by the presence of inosine in the incubating solution. Adenosine diphosphate (ADP), which was present in comparatively small amounts, showed a moderate increase at 4 weeks followed by a decline in concentration to one-third the initial level when the blood was stored in ACD. In ACDI the level of ADP increased slightly at both 4 and 8 weeks. Inosine monophosphate was found in small amounts only at 4 weeks in $\mathrm{ACD}$ and at 4 and 8 weeks in ACDI. Fructose diphosphate was not found at any time in either sample. Glucose diphosphate was surprisingly constant in concentration in ACD blood and increased somewhat in ACDI. Of possible intermediates of the pentose shunt which might be expected from the metabolism of inosine, only sedoheptulose-7-phosphate was found. In the presence of inosine, glucose-6-phosphate rose to a maximum several-fold higher than that found in the normal erythrocyte. The results are compared with those of a previous similar study of stored rabbit erythrocytes.

\section{REFERENCES}

1. Gabrio, B. W., Donohue, D. M., and Finch, C. A. Erythrocyte preservation. V. Relationship between chemical changes and viability of stored blood treated with adenosine. J. clin. Invest. 1955, 34, 1509.

2. Donohue, D. M., Finch, C. A., and Gabrio, B. W. Erythrocyte preservation. VI. The storage of blood with purine nucleosides. J. clin. Invest. 1956, 35,562 .

3. Prankerd, T. A. J. Revival of stored blood with guanosine and its successful transfusion. Lancet 1956, 1, 469.

4. Lange, R. D., Crosby, W. H., Donohue, D. M., Finch, C. A., Gibson, J. G., II, McManus, T. J., and Strumia, M. M. Effect of inosine on red cell preservation. J. clin. Invest. 1958, 37, 1485.

5. Shafer, A. W., and Bartlett, G. R. Effect of inosine on post-transfusion survival of stored rabbit erythrocytes. J. clin. Invest. 1960, 39, 69.

6. Rapoport, S. Dimensional, osmotic, and chemical changes of erythrocytes in stored blood. I. Blood preserved in sodium citrate, neutral, and acid citrate-glucose (ACD) mixtures. J. clin. Invest. 1947, 26, 591.

7. Gabrio, B. W., Hennessey, M., Thomasson, J., and Finch, C. A. Erythrocyte preservation. IV. In 
vitro reversibility of the storage lesion. J. biol. Chem. 1955, 215, 357.

8. Prankerd, T. A. J. Chemical changes in stored blood, with observations on the effects of adenosine. Biochem. J. 1956, 64, 209.

9. Rubinstein, D., Kashket, S., Blostein, R., and Denstedt, O. F. Studies on the preservation of blood. VII. The influence of inosine on the metabolic behavior of the erythrocyte during the preservation of blood in the cold. Canad. J. Biochem. 1959, 37, 69.

10. Nakao, M., Nakao, T., Tatibana, M., and Yoshikawa, H. Phosphorus metabolism in human erythrocyte. III. Regeneration of adenosine triphosphate in long-stored erythrocyte by incubation with inosine and adenine. J. Biochem. (Tokyo) 1960, 47, 661.

11. Bartlett, G. R. Human red cell glycolytic intermediates. J. biol. Chem. 1959, 234, 449.

12. Bartlett, G. R. Methods for the isolation of glycolytic intermediates by column chromatography with ion exchange resins. J. biol. Chem. 1959, 234, 459.

13. Bartlett, G. R. Phosphorus assay in column chromatography. J. biol. Chem. 1959, 234, 466.

14. Bartlett, G. R. Colorimetric assay methods for free and phosphorylated glyceric acids. J. biol. Chem. 1959, 234, 469.

15. Mills, G. C., and Summers, L. B. The metabolism of nucleotides and other phosphate esters in erythrocytes during in vitro incubation at $37^{\circ}$. Arch. Biochem. 1959, 84, 7.

16. Yoshikawa, H., Nakano, M., Miyamoto, K., and Tatibana, M. Phosphorus metabolism in human erythrocyte. II. Separation of acid-soluble phosphorus compounds incorporating $\mathrm{P}^{32}$ by column chroma- tography with ion exchange resin. J. Biochem. (Tokyo) 1960, 47, 635.

17. Gerlach, E., Fleckenstein, A., and Gross, E. Der intermediäre Phosphat-Stoff wechsel des MenschenErythrocyten. Papierchromatographische Studien unter Verwendung von ${ }^{32} \mathrm{P}$-markierten Orthophosphat. Pflïg. Arch. ges. Physiol. 1958, 266, 528.

18. Gerlach, E., and Lübben, K. Der Phosphat-Stoffwechsel in Tauben-und Menschen-Erythrocyten unter dem Einfluss von 2,4-Dinitrophenol, Natriumcyanid, Monojodacetat sowie von Thyroxin und Triäthylenmelamin. Pflïg. Arch. ges. Physiol. 1959, 269, 520.

19. Bartlett, G. R., and Shafer, A. W. Phosphate compounds of the rabbit red blood cell during storage in acid citrate dextrose (ACD) and ACD-inosine. J. clin. Invest. 1960, 39, 62.

20. Dreywood, R. Qualitative test for carbohydrate material. Industr. engin. Chem. (Anal.) 1946, 18, 499.

21. Dische, Z., and Borenfreund, E. A new spectrophotometric method for the detection and determination of keto sugars and trioses. J. biol. Chem. 1951, 192, 583.

22. Dische, Z. Qualitative and quantitative colorimetric determination of heptoses. J. biol. Chem. 1953, 204, 983.

23. Mejbaum, W. Über die Bestimmung kleiner Pentosemengen, insbesondere in Derivaten der Adenylsäure. Z. physiol. Chem. 1939, 258, 117.

24. Bartlett, G. R., and Barnet, H. N. Changes in the phosphate compounds of the human red blood cell during blood bank storage. J. clin. Invest. 1960, $39,56$. 